\title{
Correlation between $G L A$ variants and alpha-Galactosidase A profile in dried blood spot: an observational study in Brazilian patients
}

Patrícia Varela ${ }^{1}$, Gianna Mastroianni Kirsztajn², Fabiana L. Motta ${ }^{1}$, Renan P. Martin 1,3, Lauro T. Turaça', Henrique L. F. Ferrer ${ }^{1}$, Caio P. Gomes ${ }^{1}$, Priscila Nicolicht ${ }^{1}$, Maryana Mara Marins ${ }^{1}$, Juliana G. Pessoa ${ }^{1}$, Marion C. Braga ${ }^{4}$, Vânia D'Almeida ${ }^{4}$, Ana Maria Martins ${ }^{5}$ and João B. Pesquero ${ }^{1 *}$

\begin{abstract}
Background: Fabry disease is a rare X-linked inherited disorder caused by deficiency of a-Galactosidase A. Hundreds of mutations and non-coding haplotypes in the GLA gene have been described; however, many are variants of unknown significance, prompting doubts about the diagnosis and treatment. The a-Galactosidase $\mathrm{A}$ enzymatic activity in dried blood spot (DBS) samples are widely used for screening purposes; however, even when values below the normal are found, new tests are required to confirm the diagnosis. Here we describe an analysis of GLA variants and their correlation with DBS a-Galactosidase A enzymatic activity in a large Brazilian population with Fabry disease symptoms.

Results: We analyzed GLA variants by DNA sequencing of 803 male patients with suspected Fabry disease or belonging to high-risk populations; in 179 individuals, 58 different exonic variants were detected. From these, 50 are variants described as pathogenic and eight described as variants of unknown significance. The other individuals presented complex non-coding haplotypes or had no variants. Interestingly, the enzymatic activity in DBS was different among pathogenic variants and the other genotypes, including variants of unknown significance; the first presented mean of $12 \%$ of residual activity, while the others presented levels above $70 \%$ of the activity found in healthy controls.

Conclusion: The activity of a-Galactosidase A in DBS was markedly reduced in males with known pathogenic variants when compared with subjects presenting variants of unknown significance, non-coding haplotypes, or without variants, indicating a possible non-pathogenic potential of these latter genotypes. These findings bring a better understanding about the biochemical results of a-Galactosidase A in DBS samples, as well as the possible non-pathogenic potential of non-coding haplotypes and variants of unknown significance in GLA gene. These results certainly will help clinicians to decide about the treatment of patients carrying variants in the gene causing this rare but life-threatening disease.
\end{abstract}

Keywords: Fabry disease, GLA gene, Non-coding haplotypes, Molecular diagnosis, a-Galactosidase A activity, DBS enzymatic activity

\footnotetext{
* Correspondence: jbpesquero@gmail.com

${ }^{1}$ Center for Research and Molecular Diagnostic of Genetic Diseases -

Department of Biophysics, Federal University of São Paulo, Rua Pedro de

Toledo, 669 - 90 andar, São Paulo 04039-032, Brazil

Full list of author information is available at the end of the article
}

(c) The Author(s). 2020 Open Access This article is distributed under the terms of the Creative Commons Attribution 4.0 International License (http://creativecommons.org/licenses/by/4.0/), which permits unrestricted use, distribution, and reproduction in any medium, provided you give appropriate credit to the original author(s) and the source, provide a link to the Creative Commons license, and indicate if changes were made. The Creative Commons Public Domain Dedication waiver (http://creativecommons.org/publicdomain/zero/1.0/) applies to the data made available in this article, unless otherwise stated. 


\section{Background}

Fabry disease (FD - OMIM 301500) is a lysosomal storage disorder caused by pathogenic variants in the $\mathrm{X}$ linked GLA gene (Xq22.1). GLA variants may produce $\alpha$-Galactosidase A deficiency ( $\alpha-$ Gal A; EC 3.2.1.22), which is required for degradation of glycosphingolipids. Deficiency in $\alpha$-Gal A activity leads to storage of complex glycosphingolipids, mainly globotriaosylceramide (Gb3), inside of lysosomes in critical organs and tissues, impairing their functions and consequently resulting in a progressive multisystem disease, affecting people of all ethnic groups $[1,2]$.

FD presents a broad spectrum of heterogeneous clinical phenotypes, classified as classical and non-classical [3]. In the classical disease, the suspicion of FD begins with peculiar signs and symptoms such as angiokeratomas, acroparesthesia, abdominal pain, recurring headache, and progressive loss of renal function, cardiomyopathy and central nervous system microangiopathy. Non-classical phenotype frequently is associated with damage in a single organ system, principally kidney, heart and brain [4]. The clinical diagnosis of both phenotypes is challenging, since many of the main symptoms are common in other diseases [5]. Indeed, the time between the first symptoms and the diagnosis can take more than ten years.

The FD male phenotypes are directly linked to the residual $\alpha$-Gal A activity. The exact threshold value of FD pathogenicity is unknown. However, it is estimated that the cutoff for diagnosing FD is $30-35 \%$ of mean normal $\alpha$-Gal A. Some GLA mutations cause a reduction of enzyme activity to less than $10-15 \%$ of the wild type and are considered pathogenic [6]. However, others promoting a residual enzyme activity of at least $40 \%$ of the wild type protein can be considered as non-pathogenic [7].

The enzymatic activity measured in leukocytes or fibroblasts is considered a gold standard for the diagnosis of FD in male patients; however, the sample required for this analysis may be a limiting factor [8]. Thus, the analysis of $\alpha$-Gal A activity in dried blood spot (DBS) samples has been shown to be a viable alternative, especially for screening in high-risk populations; however, confirmatory tests are required for the diagnosis [9].

The FD molecular analysis is important for family segregation studies, allowing the early diagnosis of family members with pathogenic mutations, enabling the monitoring before the first symptoms and therefore promoting a better management of the symptoms of the disease in these individuals. More than 960 mutations have been reported as causing FD disease in the Human Gene $\mathrm{Mu}-$ tation Database (HGMD) [10]; however, the pathogenicity of several exonic as well as, non-coding variants (NCV) is still controversial. We describe here an observational study based on biochemical analysis performed in DBS samples and genetic analysis in male individuals with suspicion of FD presenting characteristic clinical signs or belonging to high-risk populations, as patients with unexplained renal insufficiency, left ventricular hypertrophy or stroke without a known etiology. The results of the study show the profile of GLA variants in male Brazilian patients submitted to investigation of FD and the correlation between $\alpha-G a l$ A activity and genotype.

\section{Methods}

\section{Patients and $\boldsymbol{\alpha}-\mathrm{Gal} \mathrm{A}$ activity screening}

This study included 803 male patients with suspicion of FD after clinical investigation, as well as individuals with symptoms reported as non-specific, observed in FD patients (high-risk populations). All patients were screened by $\alpha-G a l$ A enzymatic activity, determined by the hydrolysis of the substrate 4-methylumbelliferyl- $\alpha$-D-galactopyranoside in DBS samples by a fluorometric assay as described by Muller and colleagues [11]. The cut-off value of enzymatic activity (compatible with FD diagnosis) used in this screening protocol was determined in healthy Brazilian volunteers [11] and a pilot screening protocol in DBS samples from Brazilian patients of hemodialysis centers [9].

\section{DNA sequencing}

DNA was extracted from the blood sample using QIAamp DNA Blood Mini Kit (Qiagen, Hilden, Germany), according to manufacturer's instructions. Alternatively, FTA Classic Cards (Whatman ${ }^{\mathrm{Tm}}$ ) were used to facilitate the collection; DNA extraction was performed using Chelex 100 resin (Bio-Rad Laboratories, Hercules, CA, USA) according to instructions. The amplification and sequencing of the GLA regions were performed according to Varela and colleagues [12]. We analyzed the seven exons, splicing sites and the regions flanking GLA exons. The introns in their entirety, as well as the promoter region, were not sequenced in this study.

\section{Bioinformatic analysis}

Data analysis was carried out using software Geneious ${ }^{\oplus}$ (Biomatters). Sequences were compared with the reference sequence (NCBI: NG_007119 (http://www.ncbi.nih.gov) and confirmed by sequencing the reverse strand. The variants were reviewed and annotated using dbSNP - Singlenucleotide polymorphism database and HGMD - The Human Gene Mutation Database [10]. Based on this analysis, the exonic mutations were divided into described pathogenic variants and variants of unknown significance (VUS). Mutations were correlated with the likely phenotype using the dbFGP - International Fabry Disease GenotypePhenotype Database [13], previous publications and functional characterization. GnomAD - Genome Aggregation 
Database [14], 1000 Genomes Project Consortium [15] and ABraOM: Online Archive of Brazilian Mutations [16] were used to define the population frequency. The websoftware Human Splicing finder [17] was used to identify significant splicing motif alterations. Non-coding variants were also analyzed by TRAP - Transcript-inferred pathogenicity score [18].

\section{Non-coding variants analysis}

Complex non-coding haplotypes $(\mathrm{NCH})$ were assessed according to their frequency in The 1000 genomes database. Briefly, 2504 multisample (phased variant call format vcf) of the X-chromosome were filtered to rule out variants with two alleles (female sample). The remaining files that comprise 1233 samples of healthy male individuals were used as the control group. A combinatorial analysis was performed to determine the haplotypes. Complex haplotypes found in the 1000 genomes were compared to the patients to determine their frequency.

\section{Statistical analysis}

Correlation between enzyme activity and GLA sequencing were analyzed by one-way analyses of variance (ANOVA) with Turkey as post-hoc, performed using IBM SPSS ${ }^{\circ}$ software (version 18). The level of significance was set at $p<0.05$.

\section{Results}

In this study, we analyzed patients with suspicion of FD with characteristic symptoms of the disease, as well as patients belonging to high-risk populations. Most of the patients presented renal disease and were screened in dialysis clinics (93\%), while the other patients presented other symptoms that suggest FD. Details about these data are shown in Additional file 1: Table S1.

All individuals included were screened by $\alpha-G a l$ A enzymatic activity in DBS and presented low activity suggesting a possible FD diagnosis; however, other tests were requested to confirm. Of the total of males submitted to analysis, 783 were screened by enzymatic activity in DBS at the Laboratório de Erros Inatos do Metabolismo (LEIM - UNIFESP), and presented enzyme activity below the cutoff $(2.2 \mu \mathrm{mol} / \mathrm{L} / \mathrm{h})$. Other 20 patients included were screened by other laboratories, and the results are reported as positive to FD. These 20 patients presented exonic alterations; therefore, they were included in this study; however, they were not included in the statistical analysis. We performed the GLA sequencing to confirm the diagnosis.

GLA sequencing revealed 179 patients (22.3\%) with mutations in the coding regions (exons), 335 patients had no variants in the analyzed regions (41.7\%), and 289 patients $(36 \%)$ had only NCV. We found 58 previously described variants in the GLA exons; 98 patients (12.2\%) presented 50 pathogenic mutations and 81 patients (10\%) presented eight VUS. The most frequent VUS was D313Y found in 38 index cases, followed by R118C found in 30 individuals. The most frequent pathogenic mutations were R356W and M290I, found in 17 and 10 patients, respectively. A list of described variants, the enzymatic activity, functional tests, and likely phenotype is shown in Table 1.

\section{Non-coding variants}

Two hundred and eighty nine patients presented only NCV in the GLA. A list of all NCV, the population frequency and in silico predictor is shown in Additional file 2: Table S2. Seven NCV form nine NCH. To analyze the frequency of $\mathrm{NCH}$, we used data from The 1000 Genomes (only male) as the control group. Except for the haplotype c. $-10 \mathrm{C}>\mathrm{T} /$ c.370-77_370-81delCAGCC / c.640-16A > G / c.802-67G > A / c.1000-22C > T, found only in one patient of this study, all other haplotypes were also found in the control group. The results are shown in Table 2.

The most frequent haplotype is formed by the four variants c.-10C > T, c.370-77_370-81delCAGCC, c.640$16 \mathrm{~A}>\mathrm{G}$ and c. $1000-22 \mathrm{C}>\mathrm{T}$. It was found in 107 (17.1\%) patients and 125 individuals (10.1\%) in the control group. The haplotype formed by c. $-10 \mathrm{C}>\mathrm{T}$ and c. $1000-22 \mathrm{C}>\mathrm{T}$ occurred with a frequency almost fourfold higher in patients with suspected FD than in the control group. The other haplotypes present similar frequency in patients and controls.

\section{Enzymatic profile}

The correlation between the GLA variants and the $\alpha-G a l$ A activity levels were evaluated to estimate the impact of the variants in the enzyme in male patients screened by enzymatic activity in LEIM and presenting less than $2.2 \mu \mathrm{mol} / \mathrm{L} / \mathrm{h} \quad(N=783)$. The patients were divided into groups according to the classification of their mutations. Figure 1a shows the distribution of enzymatic activity per patient in each group.

Males with variants previously described as pathogenic had significantly lower enzymatic activity when compared with the other groups (mean $0.27 \mu \mathrm{mol} / \mathrm{L} / \mathrm{h}, p<0.001$ ). The VUS showed a significant decrease of residual $\alpha$-Gal A levels (mean $1.58 \mu \mathrm{mol} / \mathrm{L} / \mathrm{h}$ ) when compared with the group without variants (mean $1.73 \mu \mathrm{mol} / \mathrm{L} / \mathrm{h} ; p=0.001$ ) and the NCV group (mean $1.77 \mu \mathrm{mol} / \mathrm{L} / \mathrm{h} ; p=0.013$ ). There was no difference in $\alpha-G a l$ A levels between the group without mutation in GLA and the group with NCV $(p=0.64)$. The results are shown in Fig. $1 \mathrm{~b}$.

\section{Discussion}

GLA sequencing allows the identification of genetic mutations associated with FD and the detection of these variants is fundamental to support the diagnosis. Main 


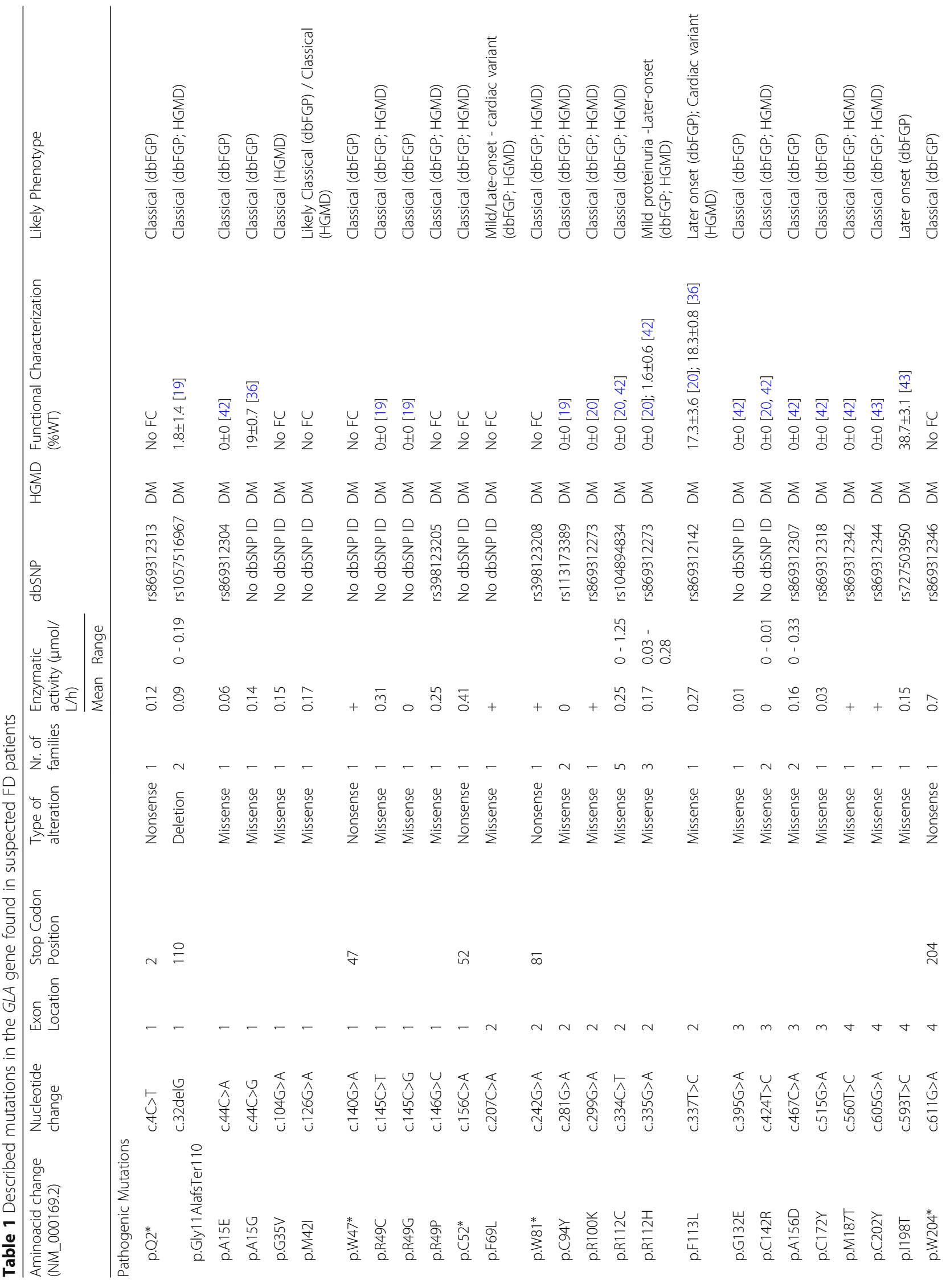




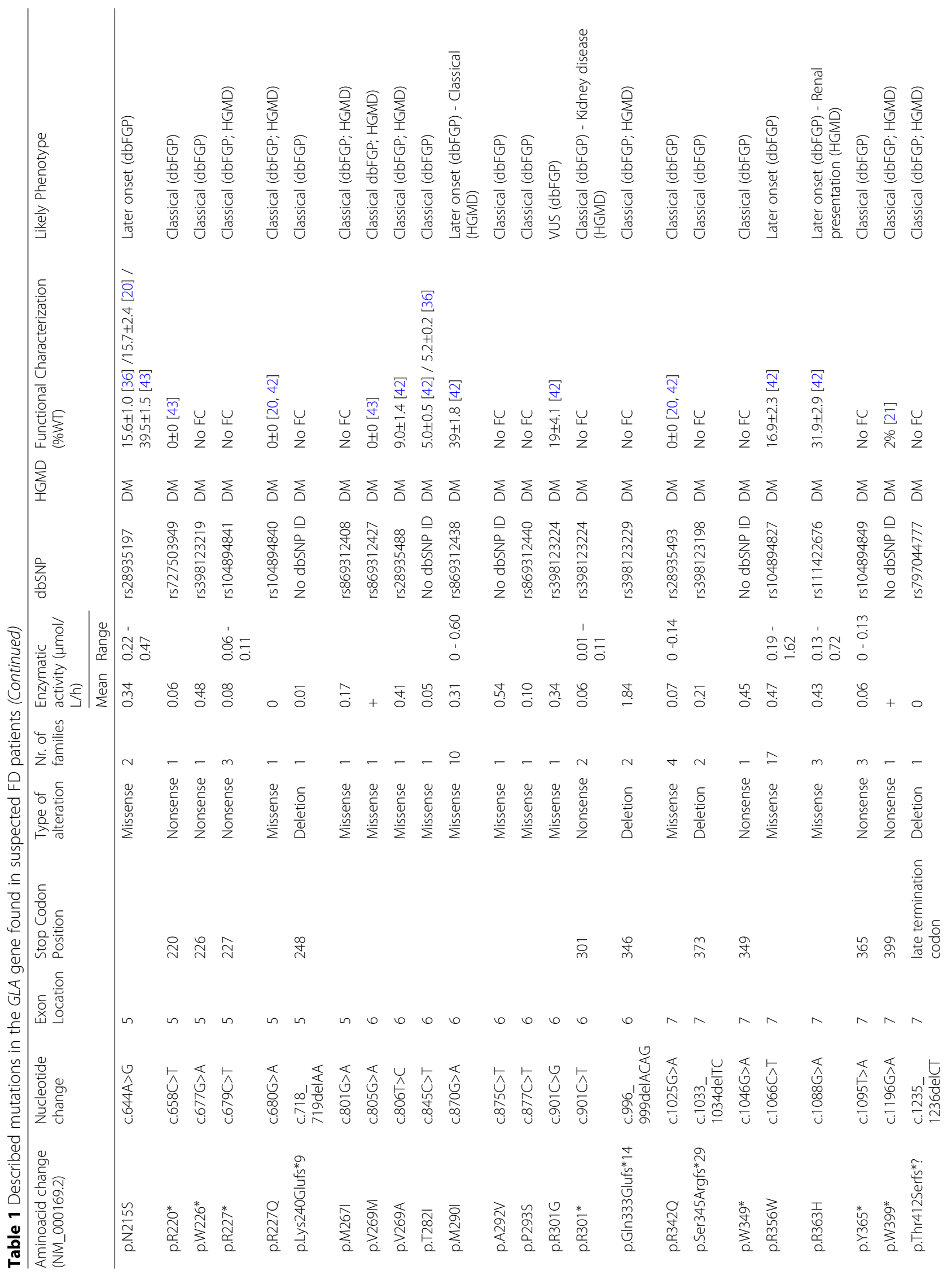




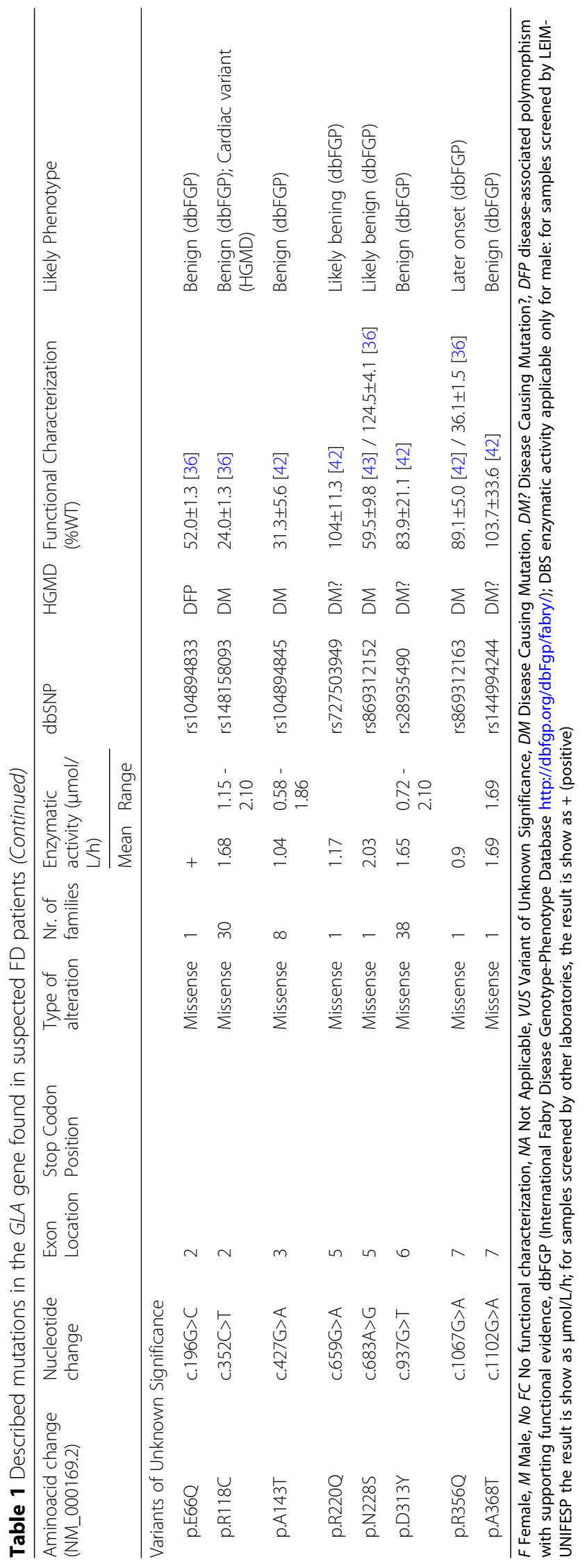




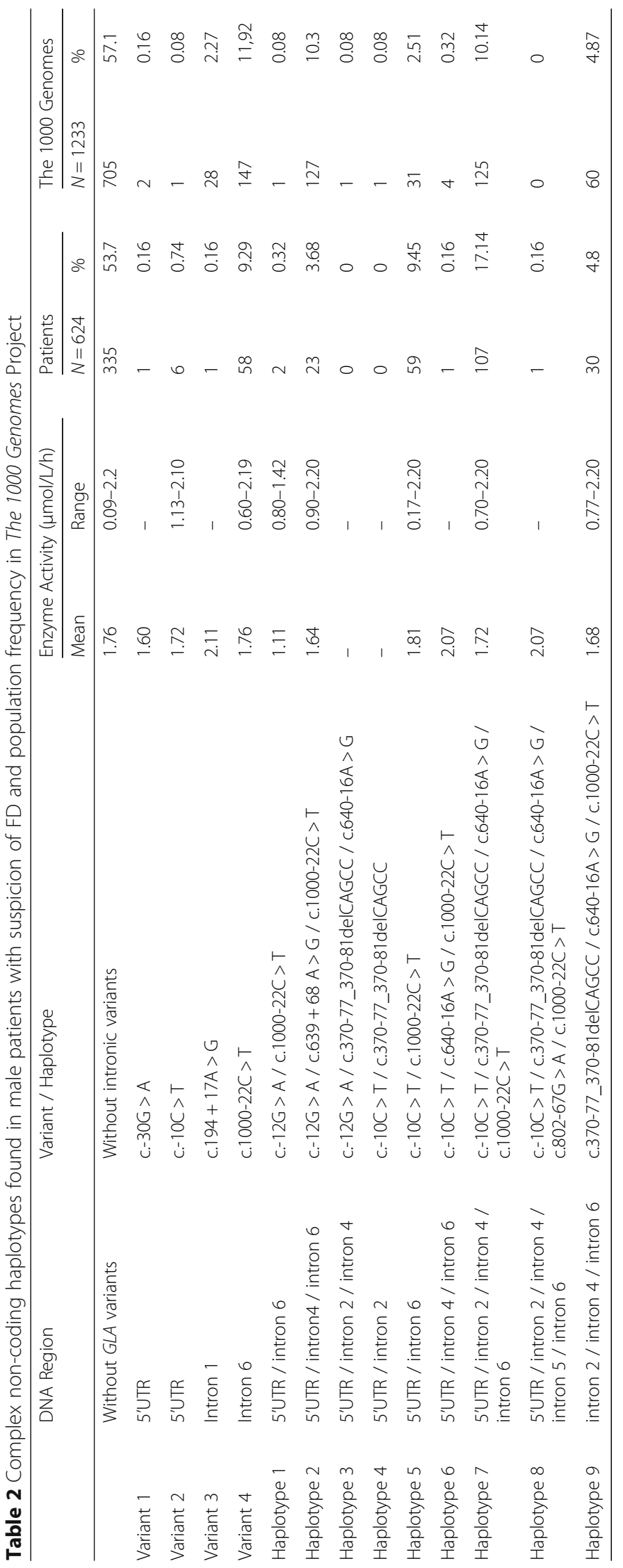




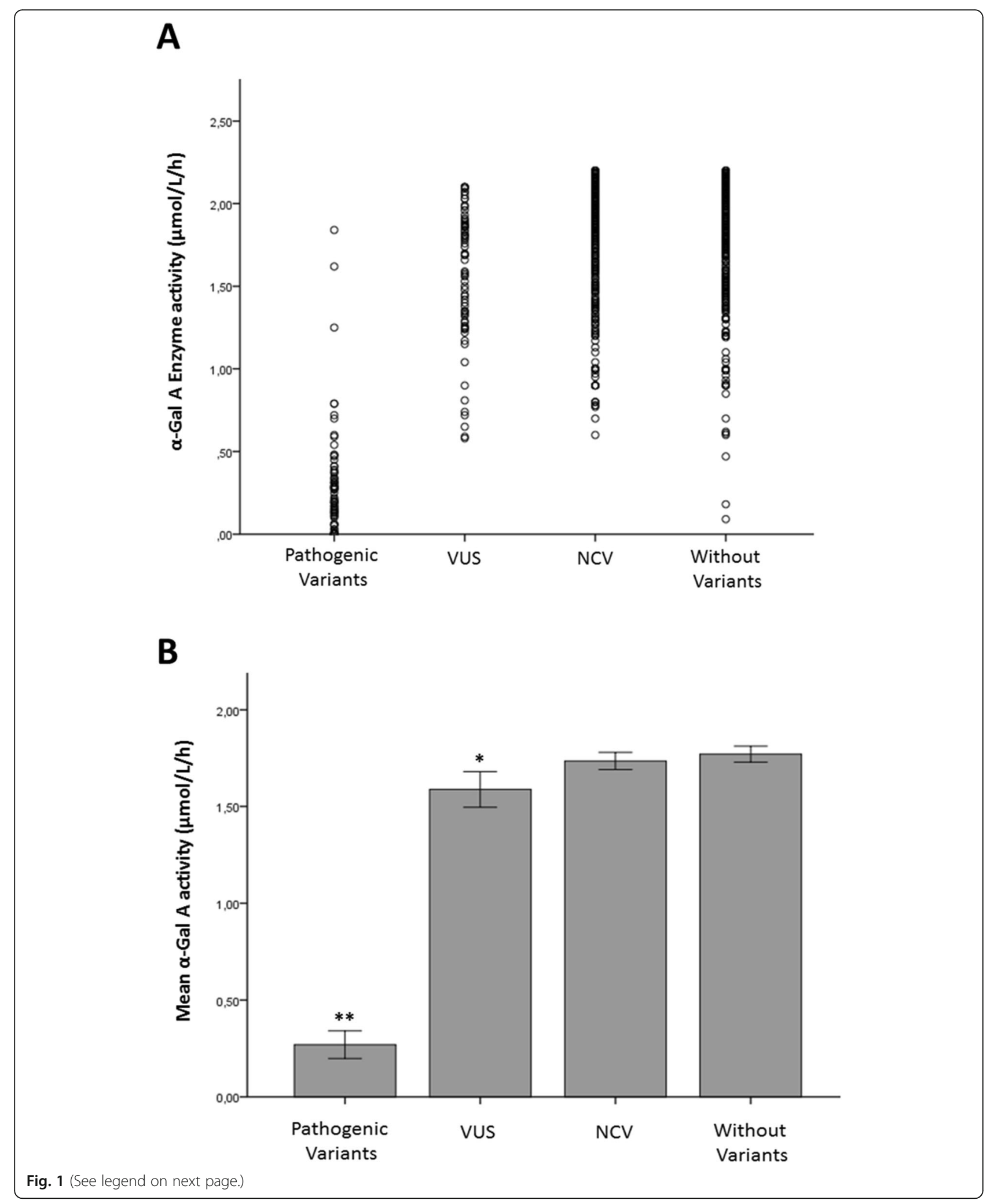


(See figure on previous page.)

Fig. 1 Enzymatic profile of GLA genotypes. (a) Scatter plot of the a-Gal A activity distribution in males with FD suspicion in different groups. The figure shows that most males with VUS, NCV and without variants present a-Gal A levels above $1 \mu \mathrm{mol} / \mathrm{L} / \mathrm{h}$, while patients with pathogenic variants presented a-Gal A levels lower than $1 \mu \mathrm{mol} / \mathrm{L} / \mathrm{h}$. Some outliers were found in each group. Three patients with pathogenic variants presented enzyme activity above $1 \mu \mathrm{mol} / \mathrm{L} / \mathrm{h}$, while twenty-four patients with only non-coding variants, twenty without variants and seven with VUS, being four with A143T, two with D313Y and one with R356Q, presented enzyme activity below $1 \mu \mathrm{mol} / \mathrm{L} / \mathrm{h}$. (b) Correlation analysis between a-Gal A level in DBS and GLA genotypes. The graphic shows the mean enzymatic activity detected in males in all the GLA variant groups. The data are expressed as mean \pm S.E.M. ${ }^{* *} P<0.001$ known pathogenic mutation $(0.27 \mu \mathrm{mol} / \mathrm{L} / \mathrm{h} \pm 0.03, N=83)$ versus VUS $(1.58 \mu \mathrm{mol} / \mathrm{L} / \mathrm{h} \pm 0.04, N=$ 76), non-coding variants $(1.73 \mu \mathrm{mol} / \mathrm{L} / \mathrm{h} \pm 0.02, N=289)$ and the group without variants in $G L A(1.77 \mu \mathrm{mol} / \mathrm{L} / \mathrm{h} \pm 0.02, N=335) ;{ }^{*} P=0.013 \mathrm{VUS}$ versus NCV and ${ }^{*} P=0.01$ VUS versus patients without variants

FD symptoms are shared with other diseases, making the diagnosis based on such symptoms challenging. The FD clinical suspicion starts with characteristic signs and symptoms that appear over the years, promoting a delay of at least 10 years to diagnose a patient [5]. Therefore, in the last two decades, the number of screening studies in high-risk and in newborn population has increased.

The $\alpha$-Gal A activity in DBS has been used for screening purposes and should be followed by enzymatic activity in leukocytes or DNA sequencing to confirm the diagnosis [9]. The efficacy of the applicability of enzymatic activity in DBS as an alternative screening test has been reported [8, 22-24]. Fuller and colleagues [25] tested DBS enzyme activity assay in FD hemizygous patients and found a clearly decrease in $\alpha$-Gal A activity when compared with a control population. A comparison between the enzymatic activity assay in DBS versus leukocytes, conducted in male patients with known FD demonstrated that both assays were equally good [26]. Here, we analyzed by DNA sequencing 803 male individuals with low enzymatic activity in DBS. All patients presented suspicion of FD after clinical investigation or showed undefined symptoms as those observed in FD patients. However, a limitation of this study was the lack of detailed information on the patient's clinic.

According to Van der Tol and coworkers [27], the prevalence of GLA variants in a high-risk population is $0.12 \%$, when considered only pathogenic variants; when VUS are included, this frequency increases to $0.62 \%$. FD is screened in dialysis centers as one possible cause of end-stage renal disease. Not surprisingly, nephrologists referred most patients included in this study, and they were predominantly followed in dialysis services. We performed the DNA sequencing only in individuals with low enzymatic activity screened by DBS assay. Interestingly, we found a high frequency of variants in our patients: $22.2 \%$ of individuals with enzymatic activity lower than $2.2 \mu \mathrm{mol} / \mathrm{L} / \mathrm{h}$ presented GLA variants. Of these, $12.2 \%$ present pathogenic variants and $10 \%$ VUS. The numbers showed here do not reflect the Van der Tol data, which could be due to the fact that here we included only patients with low activity and not those with activity within the normal range.
In addition to exonic mutations, NCV were also detected. The comparison between patients and controls showed that seven NCV were observed in more than $1 \%$ of the control population, being considered as polymorphisms. Other two variants were extremely rare or were not found in any databank consulted. Despite rare, in silico pathogenic analysis did not consider any of the $\mathrm{NCV}$ found in this study as damaging.

Nine different $\mathrm{NCH}$ were found. Seven of them presented similar frequency in patients and control group. Our results are in agreement with the findings of Ferri and colleagues [28], who found seven different GLA haplotypes in control males, indicating that these $\mathrm{NCH}$, per se, are not involved in the development of FD manifestations. However, the haplotypes 5 and 7 present higher frequency in patients when compared with controls. The haplotype 7 was already described in patients with FD suspicion $[29,30]$. Both haplotypes contain the variant c. $-10 \mathrm{C}>\mathrm{T}$, described as causing a decrease of approximately $25 \%$ of the $\alpha$-Gal A activity [31]. As described by Oliveira and colleagues [31], we also found approximately 4-fold higher frequency of this variant in our patients when compared to general population. In our study, these haplotypes were found in males with enzymatic activity below the cut-off $(\sim 1.73 \mu \mathrm{mol} / \mathrm{L} / \mathrm{h})$, equivalent to a decrease of $21 \%$ of $\alpha$-Gal A activity, indicating that c. $-10 \mathrm{C}>\mathrm{T}$ may cause this decrease. Residual enzyme activity of about $40 \%$ of the mean normal level can be considered enough to degrade the substrate, not promoting Gb3 accumulation [6, 7]. However, recent studies have demonstrated that, despite not altering the enzyme structure, patients with the haplotype 7 had significant levels of Gb3 accumulation when compared with controls [32, 33]. Gervas-Arruga and colleagues [32] suggest that in patients with this $\mathrm{NCH}$, environmental factors, as a pro-inflammatory state, in addition to the accumulation of Gb3 may influence the symptoms.

An important finding of this study was the different levels of residual activity in DBS samples among the genotypes. By comparing the mean enzymatic activity, we have observed that described pathogenic variants showed significantly lower mean enzymatic activity, equivalent to $12 \%$ of the value found in healthy 
individuals. On the other hand, VUS including D313Y, $\mathrm{R} 118 \mathrm{C}$, and A143T, considered by many researchers as not causing FD [34-39] and by others as pathogenic [40, 41], presented higher enzymatic activity in comparison to individuals with pathogenic mutations. In contrast, patients carrying VUS present enzymatic levels statistically lower when compared to patients with $\mathrm{NCV}$ or patients without mutations in GLA. In fact, in in vitro experiments, the VUS found in this study showed a decreased $\alpha-G a l$ A activity, exception for R220Q and A368T, which have $\alpha$-Gal A activity similar to that of the wild type $[36,42]$. However, data from different groups showed that this decrease is not sufficient to promote glycosphingolipid accumulation, which would lead to disease [37, 42]. Although enzymatic activity of VUS were statistically different from $\mathrm{NCH}$ and patients without variants, these genotypes present values higher than $70 \%$ of the residual activity found in health population. It is already described that activity above $40 \%$ of the level found in health population is enough to degrade Gb3, therefore our results indicate that these genotypes are not compatible with FD. However, further studies are necessary to rule out FD in these patients.

In summary, in this study we sequenced a large group of male patients with suspicion of FD presenting enzymatic activity below the cutoff $(2.2 \mu \mathrm{mol} / \mathrm{L} / \mathrm{h})$ and showed that pathogenic variants lead to a low residual enzymatic activity, while VUS, NCV and patients without GLA variants, lead to approximately $70 \%$ of the normal activity, indicating a possible non-pathogenicity. In addition, we showed, by bioinformatics correlation, that the frequency of most haplotypes formed by non-coding variants in the healthy population is similar to the frequency found in patients with suspicion of FD, and therefore, the haplotypes per se, do not correlate with FD. However, in the haplotypes most frequently observed in patients group, although presenting high levels of residual activity when compared with the pathogenic variants, other studies are necessary to discard the FD diagnosis. Moreover, the correlation between DBS enzyme activity and GLA variants revealed that this screening method is useful for diagnosing previously described mutations. However, when the patient presents VUS or $\mathrm{NCH}$, although our study indicates a possible non-pathogenicity, the diagnosis may not be conclusive and other tools may be necessary to confirm or discard the disease. Indeed, new specific studies are necessary to correlate these genotypes with FD.

\section{Conclusions}

In this observational study, we identified 98 patients with described pathogenic variants in GLA gene, confirming FD diagnosis. In these patients, the enzymatic activity in DBS samples was below $0.3 \mu \mathrm{mol} / \mathrm{L} / \mathrm{h}$, equivalent to $12 \%$ of the residual activity of healthy individuals; significantly lower when compared with the other genotypes. On the other hand, 80 patients presented only VUS, and in these cases FD diagnosis was not confirmed, as well as in patients with NCV. Our study indicates a possible nonpathogenic potential of these latter genotypes by population frequency of haplotypes and correlation between the enzymatic phenotype in DBS samples and GLA variants. These findings highlight the importance of determining $\alpha$ Gal A activity by DBS in the diagnosis of FD, considered as the only available tool for this purpose in many countries.

\section{Supplementary information}

Supplementary information accompanies this paper at https://doi.org/10. 1186/s13023-019-1274-3.

Additional file 1: Table S1. Origin of samples for FD screening according to the main symptoms

Additional file 2: Table S2. Non-coding variants found in GLA gene in patients with suspicion of FD and the population frequency in 1000 genomes, GenomAD and ABraOM. Human Splicing Finder and TRAP were used to analyze potential pathogenicity.

\section{Abbreviations}

ABraOM: Online Archive of Brazilian Mutations; dbFGP: International Fabry Disease Genotype - Phenotype Database; DBS: Dried Blood Spot; FD: Fabry Disease; Gb3: Globotriaosylceramide; GnomAD: Genome Aggregation Database; HGMD: Human Gene Mutation Database; NCH: Non-coding haplotypes; NCV: Non-coding variants; TRAP: Transcript-inferred pathogenicity score; VCF: Variant call format; VUS: Variants of unknown significance; a-GalA: a-Galalactosidase A

\section{Acknowledgements}

We would like to thank all the patients and the physicians for providing the samples analyzed in this work and Julien Calais for reviewing the English idiom.

Disclosures

The authors report no disclosures.

\section{Authors' contributions}

PV conceptualized and designed the study, designed the data collection experiments, drafted the initial manuscript, carried out the analyses, reviewed and revised the manuscript and approved the final manuscript as submitted. JBP conceptualized and designed the study, drafted the initial manuscript, carried out the initial analyses, reviewed and revised the manuscript and approved the final manuscript as submitted. JBP is corresponding author and guarantor for the article. GMK, MCB, FLM, LTT, RPM, VD and AMM carried out the initial analyses, reviewed and revised the manuscript and approved the final manuscript as submitted. CPG, HLFF, PN, MMM and JGP technical support, reviewed and revised the manuscript, and approved the final manuscript as submitted.

\section{Funding}

This work was supported by grants from Fundação de Amparo à Pesquisa do Estado de São Paulo (FAPESP 2014/27198-8 and 2018/23367-0) and Coordenação de Aperfeiçoamento de Pessoal de Nível Superior (CAPES), finance code 001.

Availability of data and materials

The datasets used and/or analyzed during the current study are available from the corresponding author on reasonable request. 


\section{Ethics approval and consent to participate}

Informed consent was obtained from all individuals included in the study. The Research Ethics Committee of the Federal University of São Paulo, Brazil approved this protocol (0585/07 and 0354/18). All procedures were followed in accordance with the ethical standards of the responsible committee on human experimentation (institutional and national) and with the Helsinki Declaration of 1975, as revised in 2013.

\section{Consent for publication}

Not applicable.

\section{Competing interests}

The authors declare no conflict of interest and confirm independence from the sponsors. The sponsors have not influenced the content of the article.

\section{Author details}

${ }^{1}$ Center for Research and Molecular Diagnostic of Genetic Diseases Department of Biophysics, Federal University of São Paulo, Rua Pedro de Toledo, 669 - 90 andar, São Paulo 04039-032, Brazil. 'Division of Nephrology - Department of Medicine, Federal University of São Paulo, São Paulo, SP, Brazil. ${ }^{3}$ McKeusick-Nathans Institute of Genetic Medicine - Johns Hopkins University School of Medicine, Baltimore, Maryland, USA. ${ }^{4}$ Department of Psychobiology, Federal University of São Paulo, São Paulo, SP, Brazil. ${ }^{5}$ Reference Center in Inborn Errors of Metabolism, Pediatrics Department, Federal University of São Paulo, São Paulo, SP, Brazil.

Received: 18 April 2019 Accepted: 5 December 2019

\section{Published online: 29 January 2020}

\section{References}

1. Auray-Blais C, Ntwari A, Clarke JTR, Warnock DG, Oliveira JP, Young SP, Millington DS, Bichet DG, Sirrs S, West ML, Casey R, Hwu WL, Keutzer J, Zhang K, Gagnon, R. How well does urinary lyso-Gb3 function as a biomarker in Fabry disease? Clin Chim Acta 2010. https://doi.org/https://doi. org/10.1016/j.cca.2010.07.038.

2. Boutin M, Gagnon R, Lavoie P, Auray-Blais C. LC-MS/MS analysis of plasma lyso-Gb3 in Fabry disease. Clin Chim Acta 2012. https://doi.org/https://doi. org/10.1016/j.cca.2012.09.026.

3. El-Abassi R, Singhal D, England JD. Fabry's disease. J Neurol Sci 2014 https://doi.org/https://doi.org/10.1016/j.jns.2014.06.029.

4. Germain DP. Fabry disease. Orphanet J Rare Dis. 2010;22:5-30. https://doi. org/10.1186/1750-1172-5-30.

5. Terryn W, Cochat P, Froissart R, Ortiz A, Pirson Y, Poppe B, Serra A, Van Biesen W, Vanholder R, Wanner C. Fabry nephropathy: indications for screening and guidance for diagnosis and treatment by the European renal best practice. Nephrol Dial Transplant 2013. https://doi.org/https://doi.org/ 10.1093/ndt/gfs526.

6. Oliveira JP, Ferreira S. Multiple phenotypic domains of Fabry disease and their relevance for establishing genotype- phenotype correlations. Appl Clin Genet. 2019. https://doi.org/. https://doi.org/10.2147/TACG.S146022.

7. Schiffmann R, Fuller M, Clarke LA, Aerts JM. Is it Fabry disease? Genet Med 2016. https://doi.org/https://doi.org/10.1038/gim.2016.55.

8. Caudron E, Prognon P, Germain DP. Enzymatic diagnosis of Fabry disease using a fluorometric assay on dried blood spots: An alternative methodology Eur J Med Genet 2015. https://doi: https://doi.org/10.1016/ej. ejmg.2015.10.014.

9. Curiati MA, Aranda, CS, Kyosen SO, Varela P, Pereira VG, D' Almeida V, Pesquero JB, Martins AM. The Challenge of Diagnosis and Indication for Treatment in Fabry Disease. J Inborn Errors Metab Screen 2017. https://doi. org/https://doi.org/10.1177/2326409816685735.

10. Stenson PD, Mort M, Ball EV, Howells K, Phillips AD, Thomas NS, Cooper DN. The human gene mutation database: 2008 update. Genome Med 2009. https://doi.org/https://doi.org/10.1186/gm13.

11. Muller KB, Rodrigues MDB, Pereira VG, Martins AM, D'Almeida V. Reference values for lysosomal enzyme activities using dried blood spots samples - a Brazilian experience. Diagn Pathol 2010. https://doi.org/https://doi.org/10. 1186/1746-1596-5-65.

12. Varela P, Mastroianni Kirsztajn, G, Ferrer H, Aranda C, Wallbach K, Mata GF et al. Functional characterization and pharmacological evaluation of a novel GLA missense mutation found in a severely affected Fabry disease family. Nephron. 2019. https://doi.org/https://doi.org/10.1159/000503998.
13. Desnick RJ, Chen R, Srinivasan R, Doheny DO, Bishop DF. The Fabry disease genotype-phenotype database (dbFGP): an international expert consortium Mol.Genet.Metab. 2017. https://doi.org/https://doi.org/10.1016/j.ymgme. 2016.11.082.

14. Lek M, Karczewski KJ, Minikel EV, Samocha KE, Banks E, Fennell T, O'DonnellLuria $\mathrm{AH}$ et al. Analysis of protein-coding genetic variation in 60,706 humans. Nat.2016. https://doi.org/https://doi.org/10.1038/nature19057

15. Auton A, Brooks LD, Durbin RM, Garrison EP, Kang HM, Korbel JO, Marchini J, McCarthy S, McVean GA, Abecasis GR. A global reference for human genetic variation. Nat. 2015. https://doi.org/https://doi.org/10.1038/ nature15393.

16. Naslavsky MS, Yamamoto GL, de Almeida TF, Ezquina SAM, Sunaga DY, Pho N, Bozoklian D, Sandberg TOM, Brito LA, Lazar M, Bernardo DV, Amaro E Jr, Duarte YAO, Lebrão ML, Passos-Bueno MR, Zatz M. Exomic variants of an elderly cohort of Brazilians in the ABraOM database. Hum Mutat 2017. https://doi.org/https://doi.org/10.1002/humu.23220.

17. Desmet FO, Hamroun D, Lalande M, Collod-Beround G, Claustre M, Beround C. Human splicing finder: an online bioinformatics tool to predict splicing signals. Nucleic Acid Res 2009. https://doi.org/https://doi.org/10.1093/nar/ gkp215.

18. Gelfman S, Wang Q, McSweeney KM, Ren Z, La Carpia F, Halvorsen M, Schoch K, Ratzon F, Heinzen EL, Boland MJ, Petrovski S, Goldstein DB. Annotating pathogenic non-coding variants in genic regions. Nat Commun 2017. https://doi.org/https://doi.org/10.1038/s41467-017-00141-2.

19. Shin SH, Murray GJ, Kluepfel-Stahl S, Cooney AM, Quirk JM, Schiffmann R, Brady RO, Kaneski CR. Screening for pharmacological chaperones in Fabry disease. Biochem Biophys Res Commun. 2007. https://doi.org/10.1016/j.bbrc. 2007.05.082

20. Wu X, Katz E., Della Valle MC, Mascioli K, Flanagan, et al. A pharmacogenetic approach to identify mutant forms of a-galactosidase $A$ that respond to a pharmacological chaperone for Fabry disease. Human mutation, 2011 https://doi.org/10.1002/humu.21530.

21. Shimotori M, Maruyama H, Nakamura G, Suyama T, Sakamoto F, Itoh M, et al. Novel mutations of the GLA gene in Japanese patients with Fabry disease and their functional characterization by active site specific chaperone. Hum Mutat. 2008. https:/doi.org/10.1002/humu.9520

22. Chamoles NA, Blanco M. Gaggioli. Fabry disease: enzymatic diagnosis in dried blood spots on filter paper. Clin Chim Acta. 2001;308(1-2):195-6. 11432396.

23. Okur I, Ezgu F, Biberoglu G. Screening for Fabry disease in patients undergoing dialysis for chronic renal failure in Turkey: identification of new case with novel mutation. Gene 15. 2013. doi: https://doi.org/10.1016/j.gene. 2013.05.050.

24. Castilhos CD, Mezzalira J, Goldim MP, Daitx W, Garcia Cda S, Andrade CV, Breier AC, Cé J, Mello AS, Coelho JC. Determination of the lysosomal hydrolase activity in blood collected on filter paper, an alternative to screen high risk populations. Gene. 2014. https:/doi: https://doi.org/10.1016/j.gene.2013.11.101.

25. Fuller M, Lovejoy M, Brooks DA, Harkin ML, Hopwood JJ, Meikle PJ. Immunoquantification of alpha-galactosidase: evaluation for the diagnosis of Fabry disease. Clin Chen 2004. https://doi:https://doi.org/10.1373/ clinchem.2004.037937.

26. Lukacs Z, Hartung R, Beck M, Mengel E. Direct comparison of enzyme measurements from dried blood and leukocytes from male and female Fabry disease patients. J. Inherit Metab Dis. 2007. https://doi::https://doi.org/ 10.1007/s10545-007-0679-7.

27. Van der Tol L, Smid BE, Poorthuis BJ, Biegstraaten M, Deprez RH, Linthorst GE, Hollak CE. A systematic review on screening for Fabry disease: prevalence of individuals with genetic variants of unknown significance. J Med Genet 2014 https://doi.org/https://doi.org/10.1136/jmedgenet-2013-101857.

28. Ferri L, Guido C, la Marca G, Malvagia S, Cavicchi C, Fiumara A, Barone R, Parini R, Antuzzi D, Feliciani C, Zampetti A, Manna R, Giglio S, Della Valle CM, Wu X, Valenzano KJ, Benjamin R, Donati MA, Guerrini R, Genuardi M, Morrone A. Fabry disease: polymorphic haplotypes and a novel missense mutation in the GLA gene. Clin Genet 2012. https://doi.org/https://doi.org/ 10.1111/j.1399-0004.2011.01689.x.

29. Tanislav C, Kaps M, Rolfs A, Bottcher T, Lackner K, Paschke E. Frequency of Fabry disease in patients with small-fibre neuropathy of unknown aetiology: a pilot study. Eur J Neurol2011. https://doi.org/https://doi.org/10.1111/j. 1468-1331.2010.03227.x

30. Pisani A, Imbriaco M, Zizzo C, Albeggiani G, Colomba P, Alessandro R. A classical phenotype of Anderson-Fabry disease in a female patient with 
intronic mutations of the GLA gene: a case report. BMC Cardiovasc Disord 2012. https://doi.org/https://doi.org/10.1186/1471-2261-12-39.

31. Oliveira JP, Ferreira S, Barceló J, Gaspar P, Carvalho F, Sá Miranda MC, Månsson JE. Effect of single-nucleotide polymorphisms of the $5^{\prime}$ untranslated region of the human a-galactosidase gene on enzyme activity, and their frequencies in Portuguese caucasians. J Inherit Metab Dis 2008. https://doi.org/https://doi.org/10.1007/s10545-008-0818-9.

32. Gervas-Arruga J, Cebolla J, Irun P, Perez-Lopez J, Plaza L, Roche J et al. Increased glycolipid storage produced by the inheritance of a complex intronic haplotype in the a-galactosidase a (GLA) gene. BMC Genet 2015. https://doi: https://doi.org/10.1186/s12863-015.0267-z.

33. Vieitez I, Souto-Rodriguez O, Fernandez-Mosquera L, San Millan B, Teijeira S, Fernandez-Martin J et al. Fabry disease in the Spanish population: observational study with detection of 77 patients. Orphanet of rare diseases 2018. https://doi:https://doi.org/10.1186/s13023-018-0792-8

34. Ferreira S, Ortiz A, Germain DP, Viana-Baptista M, Caldeira-Gomes A, Camprecios M, Fenollar-Cortés M, Gallegos-Villalobos Á, Garcia D, GarcíaRobles JA, Egido J, Gutiérrez-Rivas E, Herrero JA, Mas S, Oancea R, Péres P, Salazar-Martín LM, Solera-Garcia J, Alves H, Garman SC, Oliveira JP. The alpha-galactosidase a p.Arg118Cys variant does not cause a Fabry disease phenotype: data from individual patients and family studies. Mol Genet Metab. 2015 Feb;114(2):248-58.

35. Froissart R, Guffon N, Vanier MT, Desnick RJ, Maire I. Fabry disease: D313Y is an alpha-galactosidase A sequence variant that causes pseudodeficient activity in plasma. Mol Genet Metab. 2003 Nov;80(3):307-314.Pubmed PMID: 1468097.

36. Benjamin ER, Della Valle MC, Wu X, Katz E, Pruthi F, Bond S, Bronfin B, Williams H, Yu J, Bichet DG, Germain DP, Giugliani R, Hughes D, Schiffmann R, Wilcox WR, Desnick RJ, Kirk J, Barth J, Barlow C, Valenzano KJ, Castelli J, Lockhart DJ. The validation of pharmacogenetics for the identification of Fabry patients to be treated with migalastat. Genet. Med. 2017. https://doi. org/https://doi.org/10.1038/gim.2016.122.

37. Yasuda M, Shabbeer J, Benson SD, Maire I, Burnett RM, Desnick RJ. Fabry disease: characterization of alpha-galactosidase a double mutations and the D313Y plasma enzyme pseudodeficiency allele. Hum Mutat 2003. https:// doi.org/https://doi.org/10.1002/humu.10275.

38. Hasholt L, Ballegaard M, Bundgaard H, Christiansen M, Law I, Lund AM et al. The D313Y variant in the GLA gene - no evidence of a pathogenic role in Fabry disease. Scand J Clin Lab Invest. 2017. Htpps://doi: https://doi.org/10. 1080/00365513.2017.1390782.

39. Niemann M, Rolfs A, Giese A, Mascher H, Breunig F, Ertl G, Wanner C, Weidemann F. Lyso-Gb3 indicates that the alpha-Galactosidase a mutation D313Y is not clinically relevant for Fabry disease. JIMD Rep 2013. https://doi: https://doi.org/10.1007/8904_2012_154.

40. Spada M, Pagliardini S, Yasuda M, Tukel T, Thiagarajan G, Sakuraba H, Ponzone A, Desnick RJ. High incidence of later-onset fabry disease revealed by newborn screening Am J Hum Genet 2006. https://doi: https://doi.org/ 10.1086/504601.

41. Eng CM, Resnick-Silverman LA, Niehaus DJ, Astrin KH, Desnick RJ. Nature and frequency of mutations in the alpha-galactosidase a gene that cause Fabry disease. Am J Hum Genet. 1993;53(6):1186-97.

42. Lukas J, Giese AK, Markoff A, Grittner U, Kolodny E, Mascher H, Lackner KJ, Meyer W, Wree P, Saviouk V, Rolfs A. Functional characterization of alphagalactosidase a mutation as a basis for a new classification system in fabry disease. PLoS Genet 2013. https://doi.org/https://doi.org/10.1371/journal. pgen.1003632.

43. Lukas J, Scalia S, Eichler S, Pockrandt AM, Dehn N, Cozma C et al. Functional and Clinical Consequences of Novel a-Galactosidase A Mutations in Fabry Diseas. Hum Mut. 2015. https://doi.org/10.1002/humu.22910.

\section{Publisher's Note}

Springer Nature remains neutral with regard to jurisdictional claims in published maps and institutional affiliations.

Ready to submit your research? Choose BMC and benefit from:

- fast, convenient online submission

- thorough peer review by experienced researchers in your field

- rapid publication on acceptance

- support for research data, including large and complex data types

- gold Open Access which fosters wider collaboration and increased citations

- maximum visibility for your research: over $100 \mathrm{M}$ website views per year

At BMC, research is always in progress.

Learn more biomedcentral.com/submissions 